\title{
Ảnh hưởng của nhiệt độ nhiệt phân đến tính chất hóa lý của than sinh học từ trấu
}

\section{Effects of pyrolysis temperature on physicochemical properties of rice husk biochar}

Võ Thị Minh Thảo ${ }^{*}$, Nguyễn Minh Khánh ${ }^{1}$, Nguyễn Thị Hạnh Nguyên ${ }^{1}$, Trần Tuấn Anh ${ }^{1}$, Phạm Thị Ái Niệm ${ }^{1}$, Nguyễn Tấn Đức ${ }^{1}$, Nguyễn Ngọc Phi ${ }^{1,4}$, Nguyễn Thị Bích Tuyền ${ }^{2}$, Đoàn Ngọc Ngân ${ }^{2}$, Trần Ngọc Quốc Tường ${ }^{3}$

${ }^{1}$ Trung tâm Công nghệ sinh học Tp.HCM, Việt Nam

${ }^{2}$ Trường Đại học Tôn Đức Thắng, Việt Nam

${ }^{3}$ Trung tâm khuyến nông Tp.HCM, Việt Nam

${ }^{4}$ Trường Đại học Mở Thành phố Hồ Chí Minh, Việt Nam

*Tác giả liên hệ, Email: vothiminhthao1993@gmail.com

\section{THÔNG TIN}

DOI: 10.46223/HCMCOUJS. tech.vi.16.1.898.2021

Ngày nhận: 16/08/2020

Ngày nhận lại: 30/09/2020

Duyệt đăng: 23/10/2020

\section{Tì khóa:}

diện tích bề mặt riêng; nhiệt phân; phổ kế hồng ngoại biến đổi fourier (ftir); than sinh học; trấu

\section{TÓM TẮT}

Mục tiêu của nghiên cứu này là khảo sát ảnh hưởng của nhiệt độ nhiệt phân đến đặc tính hóa lý của than sinh học từ trấu nhằm ứng dụng trong lĩnh vực công nghệ sinh học môi trường như làm chất mang trong sản xuất chế phẩm vi sinh và vật liệu lọc thân thiện với môi trường trong xử lý nước thải. Sử dụng các phương pháp phân tích thường quy, phân tích vật liệu (SEM, FTIR, XRD, $\mathrm{BET}$ ) để đánh giá tính chất than sinh học từ trấu trong khoảng nhiệt phân từ $350-650^{\circ} \mathrm{C}$. Khối lượng riêng, $\mathrm{pH}, \mathrm{EC}$, khả năng giữ nước và độ tro của than sinh học có xu hướng tăng khi nhiệt độ nhiệt phân tăng trong khi đó hiệu suất tạo than có xu hướng giảm mạnh. Kết quả phân tích cho thấy than sinh học sau khi nung ở $550^{\circ} \mathrm{C}$ có diện tích bề mặt riêng là $42.22 \mathrm{~m}^{2} / \mathrm{g}$. Thành phần nguyên tố chủ yếu là $\mathrm{C}(10.19 \%), \mathrm{O}(52.74 \%)$ và $\mathrm{Si}(36.16 \%)$. Kết quả phân tích phổ kế hồng ngoại biến đổi Fourier (FTIR) cho thấy trên bề mặt than sinh học tồn tại liên kết $\mathrm{O}-\mathrm{H}$ (tần số $3,443.88 \mathrm{~cm}^{-1}$ ), $-\mathrm{CH} 3$ (tần số $2.360 \mathrm{~cm}^{-1}$ ), $-\mathrm{C}=\mathrm{O}$ hoặc $\mathrm{C}=\mathrm{C}$ (tần số 1,600-1,650 $\mathrm{cm}^{-1}$ ), điểm điện tích không của than ở pHPZC 6.8. Giản đồ nhiễu xạ tia $\mathrm{X}$ thấy than sinh học từ trấu có dạng carbon vô định hình khi nung ở $55^{\circ} \mathrm{C}$.

\section{ABSTRACT}

This study aims to investigate the effects of pyrolysis temperature ranged from 350 to $650^{\circ} \mathrm{C}$ on some key physicochemical properties of rice husk biochar. Based on these data, biochar production could be optimized for specific applications in environmental biotechnology, such as carriers for microorganism immobilization or disposal filter in wastewater treatment. By using material analysis techniques (SEM, FTIR, 
Keywords:

biochar; fourier transform infrared (ftir); pyrolysis; rice husk; specific surface area
$\mathrm{XRD}$, and BET) as well as conventional methods, rice husk biochars, pyrolyzed in temperature ranged of $350-650^{\circ} \mathrm{C}$, have been characterized. Particle density, $\mathrm{pH}$, EC, water holding capacity, and ash content of rice husk biochar tend to increase while biochar yield decreases sharply when increasing pyrolysis temperature. Rice husk biochar produced at $550^{\circ} \mathrm{C}$ was also determined for specific surface area, elemental composition, surface functional groups, and material structure. The results showed that biochar obtained at $550^{\circ} \mathrm{C}$ had a particular surface area of around $42.22 \mathrm{~m}^{2} / \mathrm{g}$. Elemental analysis of rice husk biochar revealed $\mathrm{C}$ (10.19\%), O (52.74\%), and $\mathrm{Si}$ (36.16\%) were dominant than other elements. Using surface functional group (FTIR) analysis, there existed the $\mathrm{O}-\mathrm{H}$ group (at frequency $\left.3,443.88 \mathrm{~cm}^{-1}\right),-\mathrm{CH}_{3}\left(2,360 \mathrm{~cm}^{-1}\right)$, and either $-\mathrm{C}=\mathrm{O}$ or $\mathrm{C}=\mathrm{C}$ group (in the range of frequency $1,600-1,650 \mathrm{~cm}^{-1}$ ); the studied rice husk biochar has its point of zero charges at $\mathrm{pH}_{\mathrm{PZC}}$ 6.8. The XRD diffractogram has presented the overall structure of rice husk biochar was amorphous in nature.

\section{Giới thiệu}

Hiện nay, than sinh học được quan tâm như một loại vật liệu rẻ tiền, thân thiện với môi trường và hiệu quả xử lý cao được dùng để cố định chất ô nhiễm trong nước và đất. Than sinh học được xem là một loại vật liệu dùng để hấp phụ bởi vì nó có những đặc tính hóa lý bao gồm khả năng trao đổi cation, có nhiều nhóm chức trên bề mặt và diện tích bề mặt riêng khá lớn (Ahmad et al., 2014). Than sinh học được sản xuất từ các loại phế phấm trong nông nghiệp như rơm rạ, trấu, xơ dừa, thân cây ngô, ... được nung theo các phương pháp như nhiệt phân, khí hóa (Lehmann, 2007; Lehmann \& Joseph, 2009; Mohanty et al., 2018). Than sinh học chứa rất nhiều vị trí hấp phụ linh động bao gồm $\mathrm{C}-\mathrm{C}, \mathrm{C}=\mathrm{C},-\mathrm{OH},-\mathrm{COOH}$, carbon mạch vòng, và một số nhóm chức chứa oxygen khác biến than sinh học thành vật liệu hấp phụ đa chức năng (Lehmann \& Joseph, 2009; Hassan et al., 2020). Những nhóm chức này rất thuận lợi cho quá trình hấp phụ các hợp chất ô nhiễm hòa tan trong nước như ammonia, nitrite và nitrate trong nước nuôi trồng thủy sản và nước thải giàu ô nhiễm hữu cơ.

Than sinh học chứa calcium, potassium, phosphorus, và những nguyên tố khác đóng vai trò hạn chế tác động của đất phèn, giúp cải thiện khả năng giữ chất dinh dưỡng, độ giữ nước, $\mathrm{pH}$ của đất, năng suất của cây trồng. Sự tác động của than sinh học đối sức khỏe đất và năng suất cây trồng thông qua kích thích hệ vi sinh vật đất hoạt động tích cực đã được ghi nhận qua nhiều nghiên cứu thực nghiệm (Anderson et al., 2011; Lehmann et al., 2011). Trong sản xuất than sinh học thì nhiệt độ nhiệt phân và nguồn nguyên liệu đầu vào là một trong những yếu tố ảnh hưởng đến tính chất hóa lý của than sinh học như $\mathrm{pH}, \mathrm{EC}$, hiệu suất tạo than, khả năng giữ nước, carbon nguyên tố, điện thế zeta (Hassan et al., 2020; Xiao, Chen, Zhu, \& Schnoor, 2018). Theo một số nghiên cứu của các tác giả trên thế giới thì nhiệt độ nhiệt phân ảnh hưởng đến sự biến đổi các nhóm cellulose, hemicellulose, lignin và thành phần vô cơ của vật liệu (Clemente, Beauchemin, Thibault, MacKinnon, \& Smith, 2018; Hassan et al., 2020). Hiện tại các công trình nghiên cứu về than sinh học ở Việt Nam vẫn còn khá mới chủ yếu là các nghiên cứu về ứng dụng than sinh học xử lý kim loại nặng, cải tạo đất nông nghiệp (Dang et al., 2017; Vinh, Nguyen, Mai, Lehmann, \& Joseph, 2014); hướng nghiên cứu của tác giả (Tran, 2016) về các đặc tính hóa lý 
của than sinh học từ trấu. Tuy nhiên, các nghiên cứu về ảnh hưởng của nhiệt độ nhiệt phân khác nhau đến tính chất hóa lý của than sinh học thì chưa nhiều. Chính vì vậy qua việc khảo sát ảnh hưởng của nhiệt độ nhiệt phân đến sự thay đổi tính chất hóa lý của than sinh học từ trấu sẽ giúp đưa ra những dữ liệu thực nghiệm cần thiết nhằm ứng dụng vật liệu này cho các quá trình xử lý nước và cải tạo đất nông nghiệp một cách hiệu quả và bền vững.

\section{Vật liệu, phương pháp nghiên cứu}

\subsection{Vật liệu nghiên cúu}

Trấu có đường kính hạt 02-03mm, chiều dài trung bình $05-08 \mathrm{~mm}$ được nung yếm khí trong lò nhiệt phân (Nabertherm model 329634) với tốc độ nâng nhiệt là $10^{\circ} \mathrm{C} /$ phút, sau khi đạt nhiệt độ cần nung thì thời gian nung giữ nhiệt trong vòng ba giờ tương ứng với các khoảng nhiệt độ từ $350^{\circ} \mathrm{C}-650^{\circ} \mathrm{C}$. Mỗi loại than sau khi nung sẽ được làm nguội trong lò nung ở nhiệt độ phòng và được trữ trong túi zipper.

\subsection{Phwơng pháp nghiên cúu}

Xác định đặc tính hóa lý của than sinh học

\subsubsection{Hiệu suất tạo than sinh học}

Hiệu suất tạo than sinh học được tham khảo theo TCVN 5335:2009, cách tính: H $(\%)=$ $\left(\mathrm{m}_{\mathrm{t}} / \mathrm{m}_{\mathrm{o}}\right) \times 100$. Khối lượng trấu và than sinh học được xác định bằng phương pháp cân trọng lượng (model B825028899). Trong đó: $\mathrm{m}_{\mathrm{t}}$ là khối lượng than sinh học sau khi nung $(\mathrm{g}) ; \mathrm{m}_{\mathrm{o}}$ là khối lượng trấu trước khi nung $(\mathrm{g})$. Thí nghiệm lặp lại ba lần.

\subsubsection{Khối luợng riêng}

Sử dụng bình tỷ trọng $\left(\mathrm{V}_{\mathrm{b}}=30.68 \mathrm{~mL}\right.$, hãng Isolab) để xác định khối lượng riêng của than sinh học theo ASTM D854 - 14: Cân và ghi nhận chính xác khối lượng bình tỷ trọng không chứa mẫu, khô và sạch $\left(\mathrm{m}_{\mathrm{b}}\right)$. Cân một lượng than sinh học vào bình (khoảng $1 / 2$ thể tích bình), cân để xác định khối lượng bình lúc sau $\left(\mathrm{m}_{\mathrm{bt}}\right.$ ), vậy lượng than trong bình là $\mathrm{m}_{\mathrm{t}}=\mathrm{m}_{\mathrm{bt}}-\mathrm{m}_{\mathrm{b}}$. Tiếp tục đưa nước cất vào bình sao cho không có bọt khí, đậy nắp cho phần nước dư tràn ra, lau khô bình và cân để xác định khối lượng bình lúc này $\left(\mathrm{m}_{\mathrm{btn}}\right)$. Vậy lượng nước trong bình là $\mathrm{m}_{\mathrm{n}}=\mathrm{m}_{\mathrm{btn}}-\mathrm{m}_{\mathrm{bt}}$. Do đó thể tích nước chiếm chỗ trong bình (có than) là $\mathrm{V}_{\mathrm{n}}=\mathrm{m}_{\mathrm{n}} / \mathrm{d}_{\mathrm{H} 2 \mathrm{O}}$ (khối lượng riêng của nước cất ở nhiệt độ phòng $\left.\mathrm{d}_{\mathrm{H} 2 \mathrm{O}}=0.99753 \mathrm{~g} / \mathrm{cm}^{3}\right)$. Xác định thể tích than $\mathrm{V}_{\mathrm{t}}=\mathrm{V}_{\mathrm{b}}-\mathrm{V}_{\mathrm{n}}(\mathrm{mL})$; do đó khối lượng riêng của than $\mathrm{d}_{\mathrm{t}}=\mathrm{m}_{\mathrm{t}} / \mathrm{V}_{\mathrm{t}}\left(\mathrm{g} / \mathrm{cm}^{3}\right)$. Thí nghiệm lặp lại ba lần.

\subsection{3. $p H$ và $E C$}

$\mathrm{pH}$ và $\mathrm{EC}(\mathrm{mS} / \mathrm{cm})$ được xác định bằng cách cân chính xác $10 \mathrm{~g}$ than sinh học vào $200 \mathrm{~mL}$ nước cất trong erlen (tỉ lệ 1:20 v/v), lắc trong 20 phút sau đó lọc chân không (Inyang et al., 2012). Mẫu nước vừa lọc được đựng vào cốc thủy tinh để đo $\mathrm{pH}$ (model $\mathrm{B} 901034544)$ và đo $\mathrm{EC}$ (model 94503055), mỗi mẫu lặp lại ba lần (TCVN 5335:2009).

\subsection{4. Độ giũu nước}

Độ giữ nước tham khảo theo ASTM D2216. Cân chính xác $10 \mathrm{~g}$ than sinh học vào phin cà phê và ấn lên bề mặt bằng một vật nặng có trọng lượng $1 \mathrm{kPa}$, lặp lại ba lần. Cho nước từ từ đến khi thấy những giọt nước đầu tiên rơi xuống đáy, nghĩa là lúc này than đã bão hòa nước. Bảo quản mẫu 24 giờ tại nhiệt độ phòng. Chuẩn bị đĩa Petri, cân khối lượng đĩa và ghi nhận số liệu. Cân $3 \mathrm{~g}$ than ướt cho vào đĩa, mỗi mẫu than ướt lặp lại ba lần. Ghi nhận chính xác lượng than ướt đã cân, sau đó đem đi sấy 24 giờ cho than khô hoàn toàn. Cân đĩa petri đã được sấy khô và ghi nhận kết quả. Độ giữ nước của than được tính theo công thức: WHC $(\%)=\left(\mathrm{m}_{\mathrm{o}}-\mathrm{m}_{1}\right) / \mathrm{m}_{1} \times 100$. 
Trong đó: $\mathrm{m}_{\mathrm{o}}=$ Khối lượng than ướt $(\mathrm{g}) ; \mathrm{m}_{1}=$ Khối lượng than khô $(\mathrm{g})$.

\subsection{5. Độ tro}

Độ tro được xác định theo ASTM D 2866-89. Đặt cốc nung trong lò nung ở nhiệt độ $650 \pm$ $25^{\circ} \mathrm{C}$ trong 01 giờ. Đặt cốc vào bình hút ẩm, làm nguội bằng nhiệt độ trong phòng và cân một lượng độ chính xác $0.1 \mathrm{mg}$. Làm khô mẫu than đó ở nhiệt độ $150 \pm 5^{\circ} \mathrm{C}$ cho đến khi thu được một trọng lượng không đổi. Cân một lượng than khô (độ chính xác $0.1 \mathrm{~g}$ ) cho vào cốc nung và đặt cốc nung vào lò ở nhiệt độ $650 \pm 25^{\circ} \mathrm{C}$. Đặt cốc nung vào bình hút ẩm và để nguội bằng nhiệt độ phòng. Sau khi mẫu vừa nguội trong bình hút ẩm, từ từ cho không khí vào tránh để tro bay. Cân lượng độ chính xác gần bằng $0.1 \mathrm{~g}$.

Công thức tính: Tổng hàm lượng tro $(\%)=[(\mathrm{D}-\mathrm{B}) /(\mathrm{C}-\mathrm{B})] \times 100$. Trong đó: $\mathrm{B}$ : trọng lượng cốc nung; $\mathrm{C}$ : trọng lượng của cốc và mẫu ban đầu; $\mathrm{D}$ : trọng lượng của cốc và mẫu hóa tro. Thí nghiệm lặp lại ba lần.

\subsubsection{Diện tích bề mặt riêng, hình ảnh vật liệu (SEM), phân tích nhóm chức (FTIR)}

Than sinh học được gửi phân tích diện tích bề mặt riêng tại Viện Khoa học Vật liệu TP.HCM, Viện Hàn lâm Khoa học và Công nghệ Việt Nam; hình ảnh vật liệu (SEM) và kết quả phân tích nhóm chức bằng phương pháp phổ hồng ngoại (FTIR) được gửi ở Viện Kỹ thuật nhiệt đới, Viện Hàn lâm Khoa học và Công nghệ Việt Nam.

\subsubsection{Thành phà̀n các nguyên tố SEM-EDS}

Đặc điểm hình thái và hóa học của nguyên tử được thực hiện bằng kính hiển vi điện tử quét kết hợp phổ tia $X$ phân tán năng lượng (SEM-EDS) với điện áp gia tốc 4,500keV của Viện Khoa học Vật liệu TP.HCM.

\subsection{8. Điểm điện tich không (PZC)}

Điểm của điện tích bằng không $(\mathrm{PZC})$ thường được mô tả là độ $\mathrm{pH}$ mà tại đó điện tích của tổng bề mặt hạt (tức là bề mặt của chất hấp thụ) bằng không (Railsback, 2006). Giá trị pH được dùng để mô tả điểm điện tích không chỉ áp dụng cho hệ $\mathrm{H}^{+} / \mathrm{OH}^{-}$, gọi là thế ion xác định. Khi $\mathrm{pH}$ nhỏ hơn giá trị $\mathrm{pH}_{\mathrm{PZC}}$, hệ được gọi là ở dưới $\mathrm{pH} \mathrm{PZC}_{\mathrm{PC}}$, khi ấy trong dung dịch nước sẽ cho ion $\mathrm{H}^{+}$nhiều hơn ion hydroxyl $\mathrm{OH}^{-}$, vì vậy bề mặt chất hấp phụ mang điện tích dương, kết quả sẽ hấp phụ anion tốt hơn. Tương tự, khi pH lớn hơn giá trị $\mathrm{pH}$ PZC, hệ được gọi là ở trên $\mathrm{pH}$ PZC, khi ấy trong dung dịch nước sẽ cho ion hydroxyl $\mathrm{OH}^{-}$nhiều hơn ion $\mathrm{H}^{+}$, vì vậy bề mặt chất hấp phụ mang điện tích âm, kết quả sẽ hấp phụ cation tốt hơn. Tham khảo theo Kragović và cộng sự (2019), để xác định điểm điện tích không của than sinh học, việc đầu tiên là chuẩn bị các dung dịch có giá trị $\mathrm{pH}_{\mathrm{i}}$ thay đổi từ $02,04,06,07,08,10,12$. Cách chuẩn bị dung dịch $\mathrm{pH}_{\mathrm{i}}$ như sau: Pha $25 \mathrm{~mL} \mathrm{KCl} 0.1 \mathrm{M}$ trong ống falcon và điều chỉnh $\mathrm{pH}$ bằng $\mathrm{HCl} 0.1 \mathrm{M}$ hoặc $\mathrm{NaOH} 0.1 \mathrm{M}$ để đạt các giá trị $\mathrm{pH}_{\mathrm{i}}$ thay đổi từ $02,04,06,07,08,10,12$. Sau đó cho $0.5 \mathrm{~g}$ than sinh học * (chất hấp phụ cần tìm $\mathrm{PZC}$ ) vào $25 \mathrm{~mL} \mathrm{KCl} 0.1 \mathrm{M}$ (tỉ lệ 1:50 w/v), lắc $250 \mathrm{rpm}$ trong 48 giờ sau đó lắng và lọc sạch huyền phù bằng giấy lọc, đo lại các giá trị $\mathrm{pH}$ tương ứng gọi là $\mathrm{pH}$. Xác định điểm điện tích không (PZC) theo công thức: $\Delta \mathrm{pH}_{\mathrm{KCl}} 0.1 \mathrm{M}=\mathrm{pH}_{\mathrm{f}}-\mathrm{pH}_{\mathrm{i}}$. Để kiểm tra ảnh hưởng của nồng độ muối $\mathrm{KCl}$ đến điểm điện tích không của than sinh học, thực hiện tương tự với cách bố trí thí nghiệm như trên với dung dịch $\mathrm{KCl} 0.01 \mathrm{M}$, từ đó tính $\Delta \mathrm{pH}_{\mathrm{KCl} 0.01 \mathrm{M}}=\mathrm{pH}_{\mathrm{f}}-\mathrm{pH}_{\mathrm{i}}$

*Than sinh học trước khi được sử dụng trong thí nghiệm xác định điểm điện tích không (PZC) được rửa theo quy trình của Fidel, Laird, và Spokas (2018). Than sinh học sau khi nung ở $550^{\circ} \mathrm{C}$ được rửa với dung dịch $\mathrm{HCl} 0.05 \mathrm{M}$ với tỉ lệ $(1: 50 \mathrm{w} / \mathrm{v})$ sau đó lắc ở tốc độ $200 \mathrm{rpm}$ trong 24 giờ để trung hòa $\mathrm{pH}$ của than vì than sau khi nung xong có $\mathrm{pH}$ cao các cation bazơ và ion 
carbonate tăng khi nhiệt độ tăng góp phần làm tăng pH (Yuan, Xu, \& Zhang, 2011). Tiếp theo, dung dịch than được lọc qua giấy lọc Whatman. Than sau khi lọc sẽ được rửa với dung dịch $\mathrm{CaCl}_{2} 0.5 \mathrm{M}$ với tỉ lệ $(1: 50 \mathrm{w} / \mathrm{v})$ ở tốc độ $200 \mathrm{rpm}$ trong 30 phút và sau đó lọc qua giấy lọc, quy trình rửa với $\mathrm{CaCl}_{2}$ được lặp lại hai lần. Tiếp theo, than sẽ được rửa lại với nước cất với tî̉ lệ $(1: 50 \mathrm{w} / \mathrm{v})$, trong 1 giờ với tốc độ $200 \mathrm{rpm}$ và được lọc qua giấy lọc, bước rửa này được lặp lại bốn lần. Than sau khi xử lý được đem đi sấy ở $65^{\circ} \mathrm{C}$ trong 72 giờ.

\subsection{9. Đặc tính cấu trúc của vật liệu (XRD)}

Đặc tính cấu trúc của vật liệu được xác định bằng phương pháp nhiễu xạ tia X $(\mathrm{XRD})$ với bức xạ $\mathrm{CuK \alpha}(\lambda=1.5405 \AA)$ trong phạm vi góc $15^{\circ} \leq 2 \theta \leq 80^{\circ}$, hoạt động ở $30 \mathrm{kV}$ và 10mA tại Viện Khoa học Vật liệu TP.HCM.

\subsection{Phuơng pháp xủ lý số liệu}

Số liệu thí nghiệm được xử lý bằng Microsoft Excel và phần mềm thống kê SAS 9.1 để phân tích ANOVA 1 yếu tố, với độ tin cậy alpha $=0.95$.

\section{Kết quả và thảo luận}

\subsection{Anh huởng của nhiệt độ đến hiệu suất tạo than sinh học}

Hiệu suất tạo than giảm dần khi nhiệt độ nhiệt phân tăng từ $350^{\circ} \mathrm{C}$ đến $650^{\circ} \mathrm{C}$ được trình bày trong Bảng 1 . Trong đó, hiệu suất tạo than sinh học giảm từ $51.75 \mathrm{a} \pm 2.52 \%$ xuống còn $35.93 \mathrm{e} \pm 1.02 \%$. Tuy nhiên, hiệu suất tạo than sinh học có khuynh hướng không thay đổi nhiều ở các khoảng nhiệt độ từ $550-650^{\circ} \mathrm{C}$ khi phân tích phương sai ANOVA 1 yếu tố do có cùng giá trị phân hạng. Các yếu tố chính quyết định năng suất và tính chất của than sinh học là tính chất vật lý, hóa học của nguyên liệu và nhiệt độ xử lý. Khi ở nhiệt độ thấp, sự phân hủy sinh khối lignocellulose xảy ra và khi nhiệt độ tăng thêm sẽ phá vỡ cấu trúc các vật liệu dễ bay hơi thành các hợp chất hữu cơ và khí thay vì than sinh học; tăng cường các phản ứng mất nước và làm giảm năng suất tạo than (Demirbas \& Arin, 2002; Mohan, Pittman, \& Steele, 2006). Hiệu suất tạo than giảm khi nhiệt độ nhiệt phân tăng của nhóm cũng tương tự với một số nghiên cứu của các tác giả (Angin, 2013; Chowdhury, Karim, Ashraf, \& Khalid, 2016). Khi nhiệt độ tăng lên, hàm lượng carbon nói chung tăng, trong khi hàm lượng $\mathrm{H}$ và $\mathrm{O}$ giảm, cho thấy mức độ carbon hóa của than sinh học tăng lên (Chun, Sheng, Chiou, \& Xing, 2004). Hàm lượng carbon tăng (tăng từ $62.2 \%$ đến $92.4 \%$ ) với sự gia tăng nhiệt độ nhiệt phân dẫn đến cấu trúc carbon cô đặc hơn trong than sinh học (Lehmann \& Joseph, 2009).

\section{Bảng 1}

Ảnh hưởng của nhiệt độ đến hiệu suất tạo than sinh học

Các nghiệm thức thí nghiệm

Nghiệm thức 1: Nhiệt độ nung $350^{\circ} \mathrm{C}$

Nghiệm thức 2: Nhiệt độ nung $400^{\circ} \mathrm{C}$

Nghiệm thức 3: Nhiệt độ nung $450^{\circ} \mathrm{C}$

Nghiệm thức 4: Nhiệt độ nung $500^{\circ} \mathrm{C}$

Nghiệm thức 5: Nhiệt độ nung $550^{\circ} \mathrm{C}$

Nghiệm thức 6: Nhiệt độ nung $600^{\circ} \mathrm{C}$
Hiệu suất tạo than (\%)

$51.75 \mathrm{a} \pm 2.52$

$47.95 \mathrm{~b} \pm 1.73$

$44.41 \mathrm{c} \pm 1.17$

$39.94 d \pm 1.00$

$37.30 \mathrm{e} \pm 1.23$

$36.96 \mathrm{e} \pm 0.66$ 


\section{Các nghiệm thức thí nghiệm}

Nghiệm thức 7: Nhiệt độ nung $650^{\circ} \mathrm{C}$

$p$-value

CV $(\%)$
Hiệu suất tạo than $(\%)$

$35.93 \mathrm{e} \pm 1.02$

$<0.001$

3.4446

Nguồn: Từ kết quả nghiên cứu của nhóm thực hiện

\subsection{Anh hưởng của nhiệt độ đến khối luọng riêng của than sinh học}

Khối lượng riêng của than sinh học từ trấu có xu hướng tăng theo nhiệt độ đến $500^{\circ} \mathrm{C}$ (từ $0.46 \mathrm{~d} \pm 0.03 \mathrm{~g} / \mathrm{cm}^{3}$ đến $\left.0.93 \mathrm{a} \pm 0.03 \mathrm{~g} / \mathrm{cm}^{3}\right)$ rồi lại giảm xuống $0.77 \mathrm{~b} \pm 0.01 \mathrm{~g} / \mathrm{cm}^{3}$ ở $650^{\circ} \mathrm{C}(\mathrm{p}<$ $0.0001)$. Ở nhiệt độ $500^{\circ} \mathrm{C}$ khối lượng riêng của than đạt cao nhất là $0.93 \mathrm{a} \pm 0.03 \mathrm{~g} / \mathrm{cm}^{3}$. Khối lượng riêng của than phụ thuộc vào vật liệu ban đầu và điều kiện sản xuất than sinh học. Ở nhiệt độ từ $550^{\circ} \mathrm{C}-650^{\circ} \mathrm{C}$ khối lượng riêng giảm do trong than lúc này có chứa nhiều cấu trúc lỗ rỗng hơn (Khanmohammadi, Afyuni, \& Mosaddeghi, 2015). Khối lượng riêng của than sinh học từ trấu ở $550^{\circ} \mathrm{C}$ là $0.81 \mathrm{~g} / \mathrm{cm}^{3}$, tương tự với kết quả của Suryaningsih, Nurhilal, Yuliah, và Salsabila (2017) là $0.86 \mathrm{~g} / \mathrm{cm}^{3}$.

\section{Bảng 2}

Ảnh hưởng của nhiệt độ đến khối lượng riêng của than sinh học

\begin{tabular}{lc}
\hline \multicolumn{1}{c}{ Các nghiệm thức thí nghiệm } & Khối lượng riêng $\left(\mathbf{g} / \mathbf{c m}^{\mathbf{3}}\right)$ \\
\hline Nghiệm thức 1: Nhiệt độ nung $350^{\circ} \mathrm{C}$ & $0.46 \mathrm{~d} \pm 0.03$ \\
Nghiệm thức 2: Nhiệt độ nung $400^{\circ} \mathrm{C}$ & $0.65 \mathrm{c} \pm 0.08$ \\
Nghiệm thức 3: Nhiệt độ nung $450^{\circ} \mathrm{C}$ & $0.80 \mathrm{~b} \pm 0.01$ \\
Nghiệm thức 4: Nhiệt độ nung $500^{\circ} \mathrm{C}$ & $0.93 \mathrm{a} \pm 0.03$ \\
Nghiệm thức 5: Nhiệt độ nung $550^{\circ} \mathrm{C}$ & $0.81 \mathrm{~b} \pm 0.03$ \\
Nghiệm thức 6: Nhiệt độ nung $600^{\circ} \mathrm{C}$ & $0.72 \mathrm{bc} \pm 0.12$ \\
Nghiệm thức 7: Nhiệt độ nung $650^{\circ} \mathrm{C}$ & $0.77 \mathrm{~b} \pm 0.01$ \\
$p$-value & $<.0001$ \\
$\mathrm{CV}(\%)$ & 8.0130 \\
\hline
\end{tabular}

Nguồn: Từ kết quả nghiên cứu của nhóm thực hiện

\subsection{Anh hưởng của nhiệt độ đến pH và EC của than sinh học}

Kết quả cho thấy giá trị $\mathrm{pH}, \mathrm{EC}$ cũng tăng theo nhiệt độ nhiệt phân tương ứng từ $7.80 \mathrm{f} \pm$ 0.00 đến $10.10 \mathrm{a} \pm 0.10$ đối với $\mathrm{pH}$ và $0.15 \mathrm{~g} \pm 0.00 \mathrm{mS} / \mathrm{cm}$ đến $0.52 \mathrm{a} \pm 0.01 \mathrm{mS} / \mathrm{cm}$ đối với $\mathrm{EC}$. Tuy nhiên ở nhiệt độ $600^{\circ} \mathrm{C}$ và $650^{\circ} \mathrm{C}$ không có khác biệt có ý nghĩa thống kê đối với giá trị pH $(\mathrm{p}<.0001)$ và $\mathrm{EC}$ tại nhiêt độ $650^{\circ} \mathrm{C}$ có giá trị cao nhất $0.52 \mathrm{a} \pm 0.01 \mathrm{mS} / \mathrm{cm}$. Giá trị $\mathrm{pH}$ và $\mathrm{EC}$ của than sinh học từ trấu khá cao khi ở nhiệt độ cao là do trong thành phần than xuất hiện nhiều nguyên tố như $\mathrm{Ca}, \mathrm{K}, \mathrm{Mg}$ có tính kiềm (Gaskin, Steiner, Harris, Da, \& Bibens, 2008). Bên cạnh đó, các nhóm chức mang tính acid bị mất đi cùng với các hợp chất dễ bay hơi khi ở nhiệt độ cao và hàm lượng các cation mang tính base cũng như ion carbonate tăng khi nhiệt độ tăng góp phần làm giá trị $\mathrm{pH}$ của than sinh học tăng cao sau quá trình nhiệt phân (Novak et al., 2009; Yuan et 
al., 2011). Ngoài ra, dưới ảnh hưởng của nhiệt độ, hàm lượng Ca có trong trấu được chuyển hóa, dễ phóng thích dạng ion $\mathrm{Ca}^{2+}$ và các ion khác làm giá trị $\mathrm{EC}$ cao (Huang, Yucheng, \& Wu, 2010).

\section{Bảng 3}

Ảnh hưởng của nhiệt độ đến $\mathrm{pH}$ và $\mathrm{EC}$ của than sinh học

\begin{tabular}{lcc}
\hline \multicolumn{1}{c}{ Nghiệm thức } & $\mathbf{p H}$ & $\mathbf{E C}(\mathbf{m S} / \mathbf{c m})$ \\
\hline Nghiệm thức 1: Nhiệt độ nung $350^{\circ} \mathrm{C}$ & $7.80 \mathrm{f} \pm 0.00$ & $0.15 \mathrm{~g} \pm 0.00$ \\
Nghiệm thức 2: Nhiệt độ nung $400^{\circ} \mathrm{C}$ & $8.13 \mathrm{e} \pm 0.10$ & $0.20 \mathrm{f} \pm 0.01$ \\
Nghiệm thức 3: Nhiệt độ nung $450^{\circ} \mathrm{C}$ & $8.40 \mathrm{~d} \pm 0.00$ & $0.25 \mathrm{e} \pm 0.02$ \\
Nghiệm thức 4: Nhiệt độ nung $500^{\circ} \mathrm{C}$ & $8.83 \mathrm{c} \pm 0.10$ & $0.28 \mathrm{~d} \pm 0.01$ \\
Nghiệm thức 5: Nhiệt độ nung $550^{\circ} \mathrm{C}$ & $9.60 \mathrm{~b} \pm 0.00$ & $0.34 \mathrm{c} \pm 0.01$ \\
Nghiệm thức 6: Nhiệt độ nung $600^{\circ} \mathrm{C}$ & $10.03 \mathrm{a} \pm 0.00$ & $0.42 \mathrm{~b} \pm 0.01$ \\
Nghiệm thức 7: Nhiệt độ nung $650^{\circ} \mathrm{C}$ & $10.10 \mathrm{a} \pm 0.10$ & $0.52 \mathrm{a} \pm 0.01$ \\
$p$-value & $<.0001$ & $<.0001$ \\
CV $(\%)$ & 0.5949 & 3.0921 \\
\hline
\end{tabular}

Nguồn: Từ kết quả nghiên cứu của nhóm thực hiện

\subsection{Anh hưởng của nhiệt độ đến khả năng giữ nước của than sinh học}

Khi nhiệt độ nhiệt phân tăng thì khả năng giữ nước có khuynh hướng tăng đáng kể từ $72.85 \mathrm{e} \pm 21.41 \%$ đến $393.06 \mathrm{a} \pm 36.69 \%$ ở nhiệt độ $350^{\circ} \mathrm{C}-550^{\circ} \mathrm{C}$, bởi vì khi nhiệt độ nhiệt phân cao dẫn đến tổng điện tích trên bề mặt than sinh học càng thấp cùng lúc với diện tích bề mặt riêng ngày càng tăng và $\mathrm{pH}$, độ tro cũng tăng cao dẫn đến khả năng giữ nước càng cao (Lima, Boateng, \& Klasson, 2010); tuy nhiên từ $500-650^{\circ} \mathrm{C}$ thì kết quả xử lý thống kê cho thấy khả năng giữ nước của than không thay đổi nhiều. Điều này có thể giải thích vì ở ngưỡng nhiệt độ này thì các hợp chất hữu cơ đã bay hơi, còn những nguyên tố khó bay hơi (như các nhóm kim loại kiềm thổ) thì vẫn chưa đạt ngưỡng bay hơi, cho nên không tạo ra nhiều không gian lỗ rỗng để giúp tăng cường khả năng giữ nước. Kết quả độ giữ nước của than sinh học được thể hiện trong Bảng 4 , ta có thể thấy rằng độ giữ nước của than sinh học được nung ở $550^{\circ} \mathrm{C}$ là cao nhất, đạt $393.06 \%$. So sánh kết quả thực nghiệm về độ giữ nước của nhóm nghiên cứu cao hơn nhiều so với nghiên cứu của (Duong et al., 2017) khi nung trấu ở $550^{\circ} \mathrm{C}$ khoảng $302.89 \%$, trong bài báo này cũng giải thích do mật độ của trấu cao nên có thể giữ được sự bốc hơi nước.

\section{Bảng 4}

Ảnh hưởng của nhiệt độ đến khả năng giữ nước của than sinh học

Các nghiệm thức thí nghiệm

Khả năng giữ nước (\%)

Nghiệm thức 1: Nhiệt độ nung $350^{\circ} \mathrm{C}$

$72.85 \mathrm{e} \pm 21.41$

Nghiệm thức 2: Nhiệt độ nung $400^{\circ} \mathrm{C}$

$243.56 \mathrm{~d} \pm 41.40$

Nghiệm thức 3: Nhiệt độ nung $450^{\circ} \mathrm{C}$

$312.16 \mathrm{c} \pm 27.70$

Nghiệm thức 4: Nhiệt độ nung $500^{\circ} \mathrm{C}$

$369.33 \mathrm{ab} \pm 10.47$ 


\section{Các nghiệm thức thí nghiệm}

Nghiệm thức 5: Nhiệt độ nung $550^{\circ} \mathrm{C}$

Nghiệm thức 6: Nhiệt độ nung $600^{\circ} \mathrm{C}$

Nghiệm thức 7: Nhiệt độ nung $650^{\circ} \mathrm{C}$

$p$-value

CV $(\%)$
Khả năng giữ nước (\%)

$393.06 \mathrm{a} \pm 36.69$

$351.72 b \pm 25.67$

$357.43 b \pm 30.93$

$<.0001$

9.7115

Nguồn: Từ kết quả nghiên cứu của nhóm thực hiện

\subsection{Anh hưởng của nhiệt độ đến độ tro của than sinh học}

Khi nhiệt độ nung tăng thì độ tro của than sinh học cũng tăng tương ứng từ $29.88 \mathrm{~g} \pm$ $0.29 \%$ (ở nhiệt độ $350^{\circ} \mathrm{C}$ ) đến $42.49 \mathrm{a} \pm 0.12 \%$ (ở nhiệt độ $600^{\circ} \mathrm{C}$ ). Vì trấu chứa hàm lượng silica rất lớn nên khi nung ở nhiệt độ càng cao thì sinh ra hàm lượng tro trong than sinh học càng cao (Mukome, Zhang, Silva, \& Six, 2013). Mặt khác, theo tác giả Angin (2013) thì độ tro phản ánh mức độ có mặt của các hợp chất không bay hơi và không cháy trong than sinh học. Khi nhiệt độ nung tăng thì hàm lượng carbon và chất vô cơ cao hơn trong khi hàm lượng thành phần chất dễ bay hơi giảm đáng kể dẫn đến nhiệt độ nhiệt phân càng tăng thì độ tro càng lớn. So sánh kết quả nghiên cứu của tác giả Prakongkep, Gilkes, Wiriyakitnateekul, Duangchan, và Darunsontaya (2013) về độ tro trung bình của trấu đạt $44 \%$ cũng khá tương đồng với kết quả nghiên cứu của nhóm.

\section{Bảng 5}

Ảnh hưởng của nhiệt độ đến độ tro của than sinh học

\section{Các nghiệm thức thí nghiệm}

Nghiệm thức 1: Nhiệt độ nung $350^{\circ} \mathrm{C}$

Nghiệm thức 2: Nhiệt độ nung $400^{\circ} \mathrm{C}$

Nghiệm thức 3: Nhiệt độ nung $450^{\circ} \mathrm{C}$

Nghiệm thức 4: Nhiệt độ nung $500^{\circ} \mathrm{C}$

Nghiệm thức 5: Nhiệt độ nung $550^{\circ} \mathrm{C}$

Nghiệm thức 6: Nhiệt độ nung $600^{\circ} \mathrm{C}$

Nghiệm thức 7: Nhiệt độ nung $650^{\circ} \mathrm{C}$

$p$-value

CV $(\%)$
Độ tro (\%)

$$
29.88 \mathrm{~g} \pm 0.29
$$

$31.18 \mathrm{f} \pm 0.44$

$34.75 \mathrm{e} \pm 0.03$

$35.21 \mathrm{~d} \pm 0.14$

$37.64 \mathrm{c} \pm 0.07$

$42.49 \mathrm{a} \pm 0.12$

$41.66 b \pm 0.04$

$<.0001$

0.5922

Nguồn: Từ kết quả nghiên cứu của nhóm thực hiện

\section{6. Đặc tính vật lý và hóa học của than sinh học tù̀ trấu ở $550^{\circ} \mathrm{C}$}

Qua các thí nghiệm về hiệu suất tạo than, khối lượng riêng, độ giữ nước, $\mathrm{pH}, \mathrm{EC}$ của than sinh học được nung ở bảy chế độ nhiệt khác nhau, nhận thấy rằng than sinh học tại nhiệt độ $550^{\circ} \mathrm{C}$ có hiệu suất tạo than và độ giữ nước tốt, đồng thời đây cũng là ngưỡng nhiệt độ phổ biến khi sản xuất than sinh học trong thực tế như theo nghiên cứu của Lehmann và Joseph (2009) thì các loại phế phụ phẩm nông nghiệp khi nung ở $550^{\circ} \mathrm{C}$ thường có tính chất hóa lý khá tốt trong 
quá trình giữ chất ô nhiễm nên nhóm nghiên cứu sẽ đánh giá các chỉ tiêu của than sinh học ở ngưỡng nhiệt độ này để cung cấp thông tin vật liệu được đầy đủ.

Ngoài ra, than sinh học dùng làm vật liệu lọc cần có khối lượng riêng lớn để đảm bảo khối lượng vật liệu trên một đơn vị thể tích sẽ lớn, đảm bảo khả năng hấp phụ chất ô nhiễm được cao hơn. Vì vậy, nhóm nghiên cứu đã tiến hành phân tích một số chỉ tiêu hóa lý trong trong than sinh học từ trấu ở $550^{\circ} \mathrm{C}$ được trình bày trong Bảng 6 , trong đó hàm lượng carbon nguyên tố đạt $56.4 \%$, hàm lượng tổng nitrogen đạt $0.87 \%$, hàm lượng $\mathrm{K}_{2} \mathrm{O}$ và $\mathrm{P}_{2} \mathrm{O}_{5}$ dễ tiêu đạt $1.15 \%$ và $0.054 \%$ điều này chứng tỏ than sinh học từ trấu sau quá trình carbon hóa vẫn còn hàm lượng dinh dưỡng từ đó tạo điều kiện cho việc cố định vi sinh vật trên mạch than và cải tạo đất nông nghiệp. Ngoài ra, nhóm cũng đã tiến hành xác định các thông số vật lý và hóa học phức tạp như diện tích bề mặt riêng, nhóm chức và cấu trúc lỗ của vật liệu than sinh học, chụp XRD để có giải thích kĩ về cơ chế hấp phụ chất ô nhiễm của than sinh học.

\section{Bảng 6}

Kết quả phân tích một số chỉ tiêu hóa lý của than sinh học từ trấu

\begin{tabular}{ccccc}
\hline STT & Chỉ tiêu & Đơn vị & Kết quả & Phương pháp thử \\
\hline 1 & Độ ẩm & $\%$ & 5.01 & \\
& & & $\left(\right.$ Sấy ở $\left.105^{\circ} \mathrm{C}\right)$ & TCVN 9297:2012 \\
2 & $\mathrm{C}$ & 56.4 & \\
& & $\%$ & $($ Kết quả tính trên mẫu sấy & TOC-V Analyzer \\
3 & Tổng N & khô $\left.105^{\circ} \mathrm{C}\right)$ & \\
4 & $\mathrm{~K}_{2} \mathrm{O}$ hữu hiệu & $\%$ & 0.87 & TCVN 8557:2010 \\
5 & $\mathrm{P}_{2} \mathrm{O}_{5}$ hữu hiệu & $\%$ & 1.15 & TCVN 8560:2010 \\
6 & Calci $(\mathrm{Ca})$ & $\mathrm{mg} / \mathrm{kg}$ & 0.054 & TCVN 8559:2010 \\
7 & Magnesium $(\mathrm{Mg})$ & $\mathrm{mg} / \mathrm{kg}$ & 2491 & TCVN 9284:2012 \\
8 & Đồng $(\mathrm{Cu})$ & $\mathrm{mg} / \mathrm{kg}$ & 557 & TCVN 9285:2012 \\
9 & Sắt $(\mathrm{Fe})$ & $\mathrm{mg} / \mathrm{kg}$ & 10.7 & TCVN 9286: 2012 \\
10 & Kẽm $(\mathrm{Zn})$ & $\mathrm{mg} / \mathrm{kg}$ & 817 & TCVN 9283:2012 \\
11 & Manganese $(\mathrm{Mn})$ & $\mathrm{mg} / \mathrm{kg}$ & 61.0 & TCVN 9289:2012 \\
12 & SiO 2 & 173 & TCVN 9288:2012 \\
\hline
\end{tabular}

Nguồn: Từ kết quả nghiên cứu của nhóm thực hiện

\subsubsection{Diện tích bề mặt than sinh học tì trấu}

Kết quả xác định diện tích bề mặt riêng của của than sinh học từ trấu là $42.22 \mathrm{~m}^{2} / \mathrm{g}$ trong khoảng áp suất tương đối p/po từ 0.008 đến 0.358 ; tương ứng với thể tích hấp phụ từ $5.99 \mathrm{~cm}^{3} / \mathrm{g}$ đến $14.72 \mathrm{~cm}^{3} / \mathrm{g}$. Diện tích bề mặt hấp phụ và giải hấp phụ $\mathrm{N}_{2}$ tối đa đạt $61.13 \mathrm{~m}^{2} / \mathrm{g}$ và $29.11 \mathrm{~m}^{2} / \mathrm{g}$. Kích thước lỗ rỗng hấp phụ và giải hấp phụ trung bình đạt $0.23 \mathrm{~nm}$ và $0.12 \mathrm{~nm}$ có đường kính nhỏ hơn $02 \mathrm{~nm}$ nên được xếp vào kích thướng lỗ micropore hay còn gọi và kích thước lỗ vi mao quản rất thích hợp cho quá trình hấp phụ. Theo Claoston, Samsuri, Husni, và Amran (2014) than sinh 
học từ trấu khi được nhiệt phân ở $500^{\circ} \mathrm{C}$ và biến tính thì đạt đến $230.91 \mathrm{~m}^{2} / \mathrm{g}$. Trong một nghiên cứu khác, than sinh học được tạo ra bằng phương pháp nhiệt phân chậm ở $500^{\circ} \mathrm{C}$ trong 04 giờ đạt $12.2 \mathrm{~m}^{2} / \mathrm{g}$ (Wang et al., 2013). Điều này cho thấy diện tích bề mặt riêng của than sinh học phụ thuộc rất nhiều vào phương pháp sản xuất và hậu xử lý.

\subsubsection{Thành phần nguyên tố của than sinh học tù̀ trấu}

Kết quả về thành phần nguyên tố và tỉ lệ phần trăm về khối lượng của than sinh học từ trấu được xác định thông qua phương pháp tán xạ năng lượng tia X (SEM-EDS) như sau: hàm lượng $\mathrm{C}(10.19 \%), \mathrm{O}(52.74 \%), \mathrm{Al}(0.38 \%), \mathrm{Si}(36.16 \%)$ và $\mathrm{K}(0.53 \%)$ ứng với nhiệt độ nung là $550^{\circ} \mathrm{C}$. Nghiên cứu của Armynah, Atika, Djafar, Piarah, và Tahir (2018) cho thấy các thành phần nguyên tố chính của than sinh học từ trấu ở các nhiệt độ nung khác nhau thì khác nhau cụ thể là ở nhiệt độ $250^{\circ} \mathrm{C}$ thì $\mathrm{C}(22.33 \%), \mathrm{O}(41.22 \%), \mathrm{Na}(0.04 \%), \mathrm{Mg}(0.04 \%), \mathrm{Al}(0.41 \%), \mathrm{Si}(35.8 \%)$, $\mathrm{K}(0.15 \%), \mathrm{Ca}(0.01 \%)$; ở nhiệt độ $350^{\circ} \mathrm{C}$ có C $(7.72 \%), \mathrm{O}(48.79 \%), \mathrm{Na}(0.05 \%), \mathrm{Mg}(0.14 \%)$, Al (0.25\%), Si (42.4\%), K (0.54\%), Ca (0.11\%) và 450 ${ }^{\circ} \mathrm{C}$ là C (6.15\%), O (49.04\%), Mg $(0.23 \%), \mathrm{Al}(0.47 \%), \mathrm{Si}(42.14 \%), \mathrm{K}(1.65 \%), \mathrm{Ca}(0.33 \%)$. Dựa vào nghiên cứu của tác giả nhận thấy khi nhiệt độ nhiệt phân tăng thì hàm lượng $\mathrm{C}$ giảm trong khi đó thành phần $\mathrm{O}$ và nhóm vi lượng tăng. Như vậy, ở các nhiệt độ nung khác nhau thì thành phần nguyên tố cũng khác nhau.

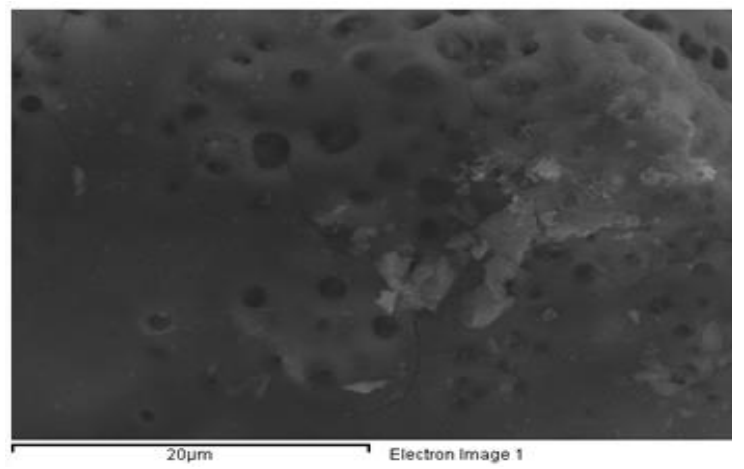

Hình 1. Lỗ xốp của vật liệu

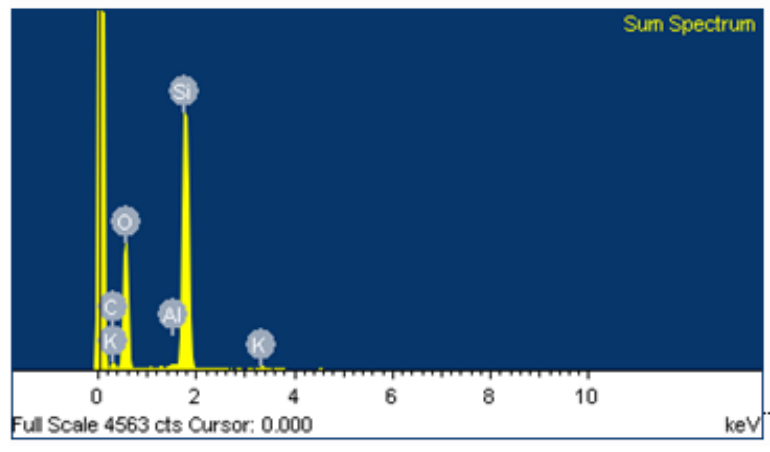

Hình 2. Giản đồ tán xạ năng lượng tia $\mathrm{X}$ (SEM-EDS) của than sinh học từ trấu ở $550^{\circ} \mathrm{C}$

\subsubsection{Cấu trúc bề mặt của than sinh học tì̀ trấu}

Than sinh học từ trấu được chụp bằng kính hiển vi điện tử quét phát xạ trường (SEM) có độ phóng đại lần lượt là $500,1,000$ và 3,000 lần, với ống phát điện từ trường phát xạ làm việc ở $05 \mathrm{kV}$, khoảng cách làm việc WD $08 \mathrm{~mm}$.

Ảnh bề mặt bên trong và bên ngoài vật liệu cho thấy than sinh học có dạng lỗ rỗng, xốp, chứa nhiều vi lỗ kích thước từ $0.12-0.23 \mathrm{~nm}$, điều này rất có lợi cho quá trình hấp phụ giúp than sinh học có thể giữ được nhiều chất ô nhiễm hơn trong các lỗ rỗng.

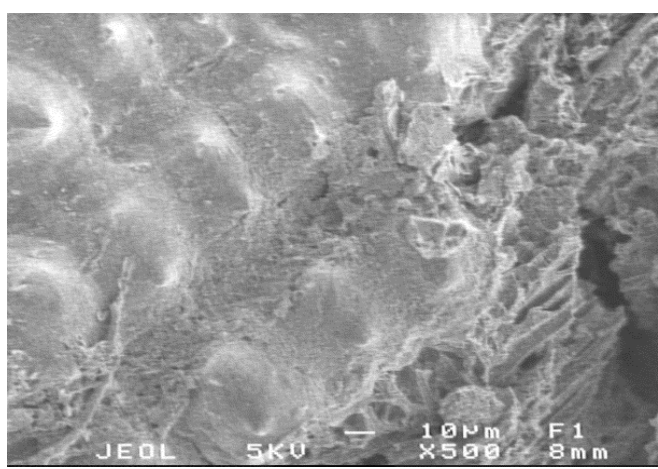

Độ phóng đại (x 500). Bar = 10um

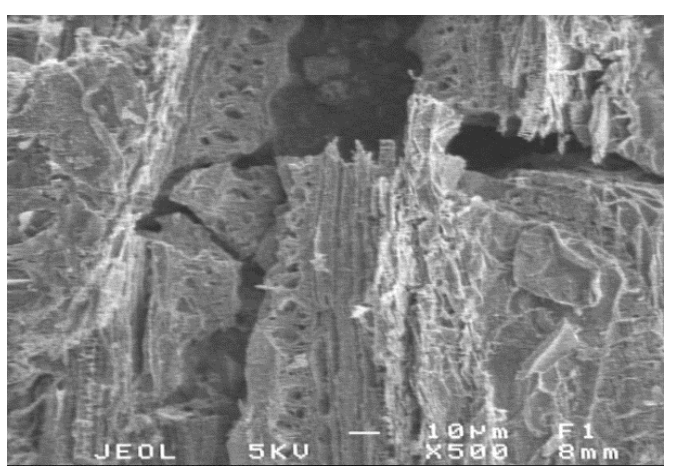

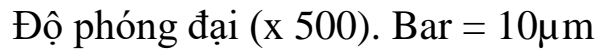




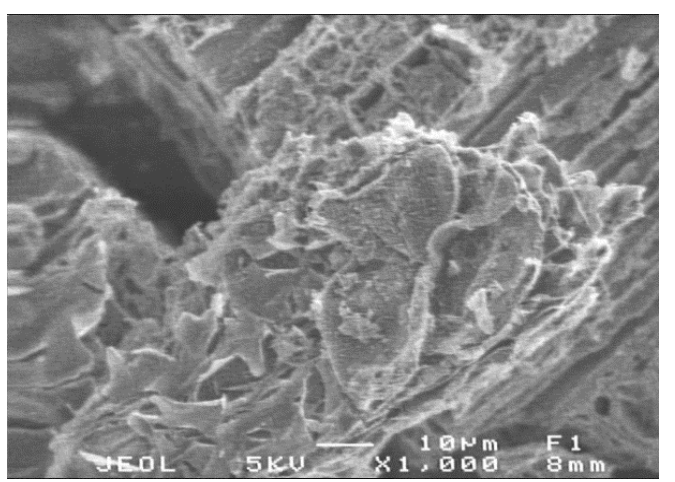

Độ phóng đại (x 1000). Bar = 10 $\mu \mathrm{m}$

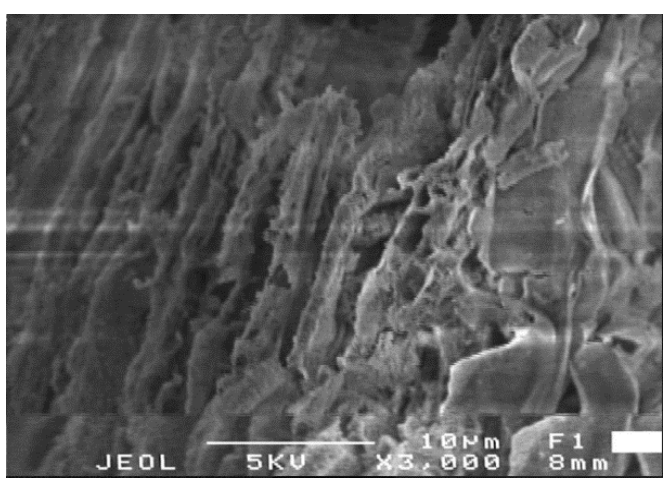

Độ phóng đại (x 3000). Bar = 10 $\mu \mathrm{m}$

Hình 3. Ảnh chụp kính hiển vi điện tử quét (SEM) của than sinh học từ trấu

\subsubsection{Xác định nhóm chức trên bề mặt than sinh học tù̀ trấu bằng phổ FTIR}

Kết quả phân tích cho thấy trên bề mặt than sinh học tồn tại liên kết O-H (tần số $3,443.88 \mathrm{~cm}^{-1}$ ), $-\mathrm{CH}_{3}$ (tần số $2,360 \mathrm{~cm}^{-1}$ ),$-\mathrm{C}=\mathrm{O}$ hoặc $\mathrm{C}=\mathrm{C}$ (tần số $1,600-1,650 \mathrm{~cm}^{-1}$ ). Peak tại tần số $1,456 \mathrm{~cm}^{-1}$ là đặc trưng cho nhóm $-\mathrm{COOH}$ thường thấy do quá trình phản ứng của nhóm $\mathrm{OH}^{-}$ và nhóm $\mathrm{C}=\mathrm{O}$. Trong đồ thị xuất hiện vùng peak $\alpha$ (bao gồm các peak tại tần số $1,098 \mathrm{~cm}^{-1}$ và $795 \mathrm{~cm}^{-1}$ ) là các peak đặc trưng cho ion $\mathrm{CO}_{3}{ }^{2-}$ (Regnier, Lasaga, Berner, Han, \& Zilm, 1994). Theo nghiên cứu của tác giả Armynah và cộng sự (2018) cho thấy ở các nhiệt độ nung khác nhau thì sự phân bố các nhóm chức của than sinh học từ trấu cũng khác nhau cụ thể: ở peak $3,452 \mathrm{~cm}^{-1}$ là nhóm $\mathrm{O}-\mathrm{H}$ kéo dài đặc trưng cho nước ở trong bề mặt vật liệu hoặc khoáng chất khác có nguồn gốc từ nhóm hydroxyl. Cường độ peak hydroxyl giảm dần khi nhiệt độ tăng từ $350^{\circ} \mathrm{C}$ đến $450^{\circ} \mathrm{C}$ điều này có thể là do nguyên tử hydrogen và oxygen trong liên kết hydroxyl bị đứt gãy. Nhóm vòng thơm từ lignin tạo ra $\mathrm{C}=\mathrm{C}$ kéo dài không đối xứng ở $1,612 \mathrm{~cm}^{-1}$ tương ứng với liên kết của các nguyên tử carbon. Liên kết uốn $\mathrm{C}-\mathrm{H}$ ở $872 \mathrm{~cm}^{-1}$ giảm và tạo $\mathrm{ra}^{\mathrm{C}} \mathrm{H}_{4}$ dưới dạng khí có nhiệt độ tăng từ $250^{\circ} \mathrm{C}$ đến $450^{\circ} \mathrm{C}$. Việc phân tích FTIR sẽ xác định được các nhóm chức khác nhau trên bề mặt than sinh học khác nhau từ đó lựa chọn loại than sinh học có khả năng hấp phụ được các chất độc hại như ammonia, nitrite, nitrate, thuốc trừ sâu, kháng sinh, kim loại nặng. Từ đó sẽ hỗ trợ quá trình phân giải sinh học nhờ hệ vi sinh vật khi được cố định trên than trong các ứng dụng xử lý nước thải. 


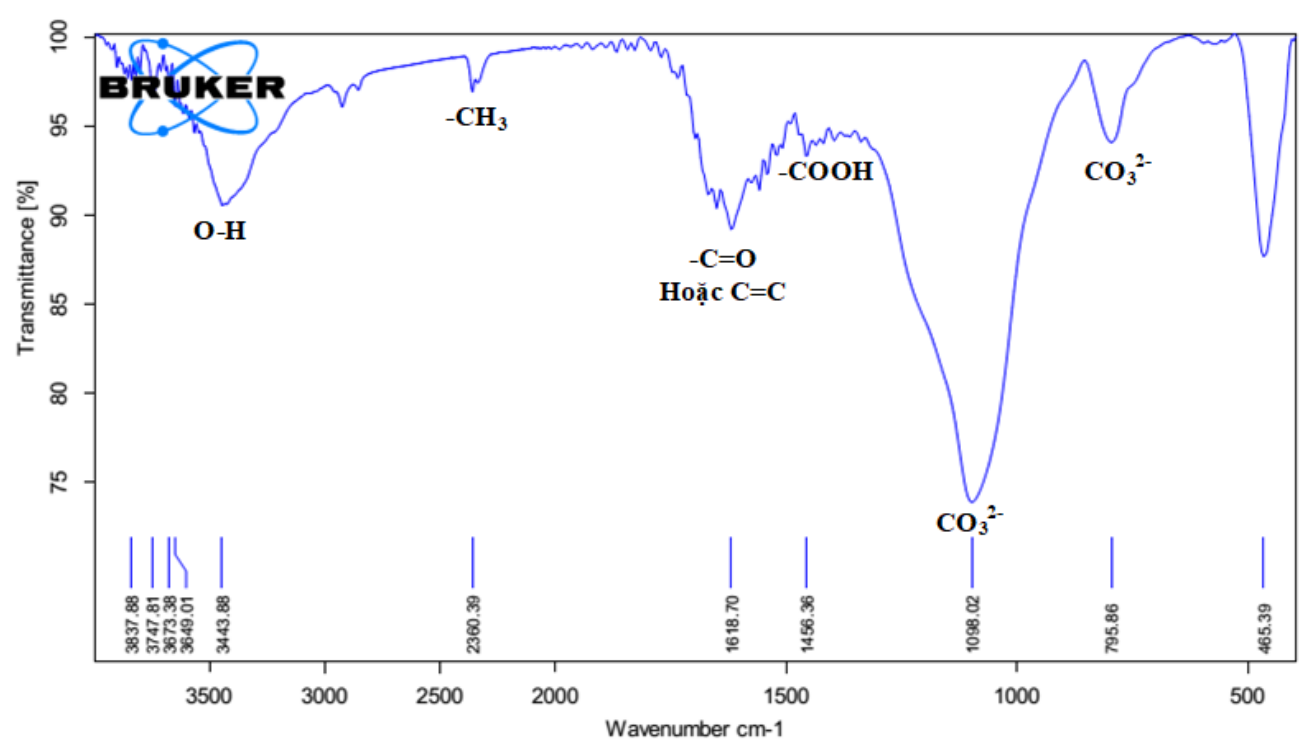

Hình 4. Kết quả phân tích nhóm chức trên bề mặt than sinh học từ trấu bằng phương pháp phổ hồng ngoại FTIR

\subsection{5. Điểm điện tích không của than sinh học tù trấu}

Điểm điện tích không (PZC) đối với một bề mặt khoáng vật là giá trị pH tại đó vật liệu có điện tích trung hòa toàn phần. Vì thế, mục đích xác định điểm $\mathrm{pH}$ PZC trong nghiên cứu này nhằm phục vụ cho việc giải thích cách thức hấp phụ các ion trong môi trường nước khi tương tác với than sinh học như là vật liệu hấp phụ. Thí nghiệm xác định điểm điện tích không của than sinh học từ trấu nung ở $550^{\circ} \mathrm{C}$ cho thấy giá trị $\mathrm{pH}$ PZC của than sinh học là 6.8 .

Đối với nền là $\mathrm{KCl} 0.1 \mathrm{M}$ thì ở $\mathrm{pH} 6.8$ ta có $\Delta \mathrm{pH} \mathrm{PZC} / \mathrm{KCl}_{0.1 \mathrm{M}}=0.07$ trong khi đó nền $\mathrm{KCl}$ $0.01 \mathrm{M}$ thì $\Delta \mathrm{pH} \mathrm{PZC} / \mathrm{KCl}_{0.01 \mathrm{M}}=0.04$. Do đó $\mathrm{pH}$ PZC của than sinh học với cùng một loại muối ít phụ thuộc vào nồng độ của muối đó. Như vậy, $\mathrm{pH}$ thực tế của than sinh học từ trấu sau khi được xử lý theo Fidel và cộng sự (2018) đạt giá trị $6.11 \pm 0.09<$ pHPZC 6.8 nên bề mặt của than sinh học (chất hấp phụ) mang điện tích dương, khả năng hấp phụ tốt các anion trong môi trường.

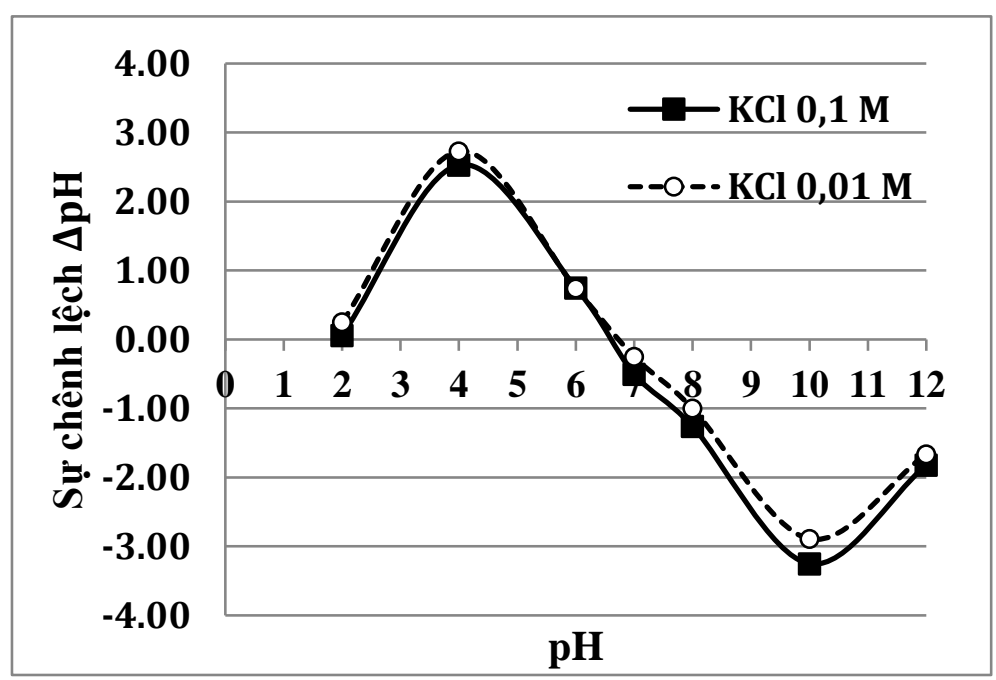

Hình 5. Đồ thị xác định điểm điện tích không (PZC) của than sinh học từ trấu ở pH từ 02-12 


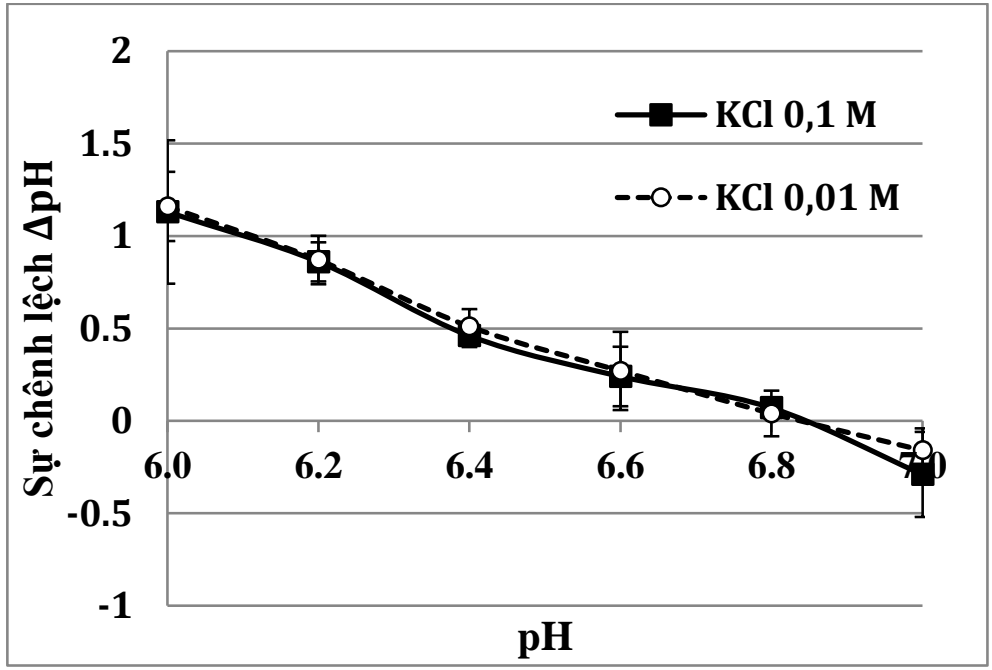

Hình 6. Đồ thị xác định điểm điện tích không (PZC) của than sinh học từ trấu ở pH từ 06-07

\subsection{6. Đặc tính cấu trúc của vật liệu (XRD)}

Giản đồ nhiễu xạ tia X (XRD) của than sinh học từ trấu ở Hình 7 cho thấy than sinh học có dạng carbon vô định hình do có đỉnh rộng ở góc $2 \theta=22^{\circ}$ và không xác định được đỉnh peak khoáng do chưa hình thành pha kết tinh. Kết quả này cũng tương tự với nghiên cứu của tác giả Tran (2016) cho thấy than sinh học từ trấu cũng là dạng carbon vô định hình do có đỉnh rộng ở góc $2 \theta=10^{\circ}$ và tác giả Armynah và cộng sự (2018) có than sinh học từ trấu nung ở nhiệt độ $250^{\circ} \mathrm{C}$ và $350^{\circ} \mathrm{C}$ cũng là dạng carbon vô định hình ở $2 \theta=22^{\circ}$.

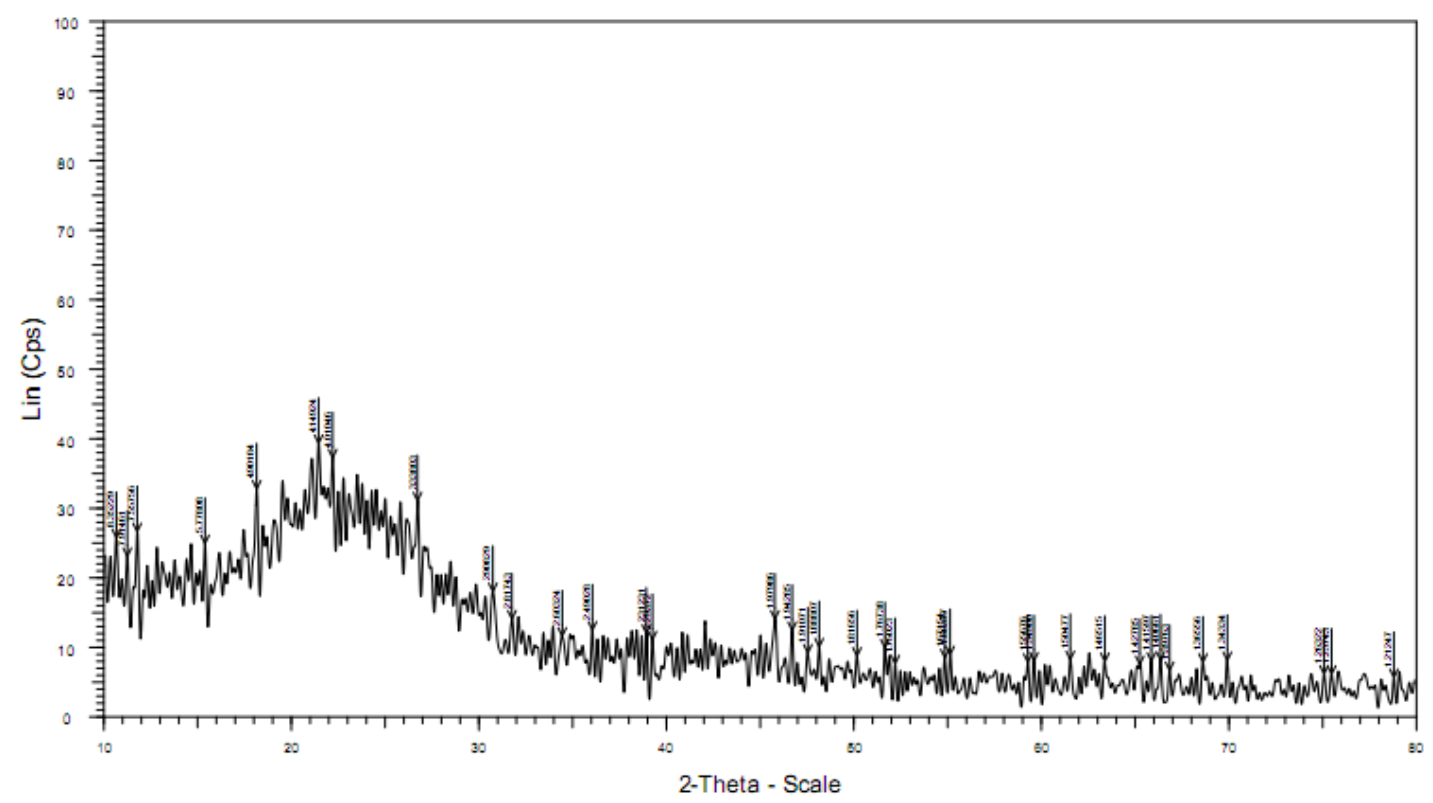

Hình 7. Giản đồ nhiễu xạ tia $X(X R D)$ của than sinh học từ trấu ở nhiệt độ $550^{\circ} \mathrm{C}$

\section{Kết luận}

Tính chất vật lý và hóa học của than sinh học từ trấu ở các nhiệt độ nung khác nhau thì không giống nhau cụ thể là hiệu suất tạo than giảm đáng kể từ $51.75 \%$ xuống còn $35.93 \%$ ở nhiệt độ từ $350^{\circ} \mathrm{C}$ đến $650^{\circ} \mathrm{C}$; khối lượng riêng có xu hướng tăng theo nhiệt độ đến $500^{\circ} \mathrm{C}$ (đạt cao nhất là $\left.0.93 \mathrm{~g} / \mathrm{cm}^{3}\right)$; giá trị $\mathrm{pH}$ và $\mathrm{EC}$ tăng dần theo nhiệt độ nhiệt phân tương ứng từ 7.8 đến 10.10 (đối với $\mathrm{pH}$ ) và 0.15 đến; $0.52 \mathrm{mS} / \mathrm{cm}$ (đối với $\mathrm{EC}$ ); khả năng giữ nước của than sinh học ở $550^{\circ} \mathrm{C}$ là cao nhất đạt $393.06 \%(\mathrm{w} / \mathrm{w})$ và ở nhiệt độ càng cao thì độ tro càng lớn trung bình từ 
$29.88 \%$ (ở $350^{\circ} \mathrm{C}$ ) đến $42.49 \%$ (ở $600^{\circ} \mathrm{C}$ ). Riêng đối với than sinh học nung ở $550^{\circ} \mathrm{C}$, kết quả cho thấy diện tích bề mặt riêng đạt $42.22 \mathrm{~m}^{2} / \mathrm{g}$; vật liệu có cấu trúc rỗng, xốp với kích thước nhỏ từ $0.12-0.23 \mathrm{~nm}$; nhóm chức đặc trưng $\mathrm{C}=\mathrm{C}$ và $\mathrm{O}-\mathrm{H}$; điểm điện tích không tại $\mathrm{pH} 6.8$ và từ phổ XRD cho thấy than có dạng carbon vô định hình. Từ kết quả thực nghiệm về những đặc tính của than sinh học từ trấu sẽ hướng đến ứng dụng than sinh học trong xử lý môi trường như làm vật liệu lọc hấp phụ chất ô nhiễm, cải tạo đất nông nghiệp thông qua khả năng giữ nước tốt và cố định vi sinh vật.

\section{Tài liệu tham khảo}

Ahmad, H., Rajapaksha, A. U., Lim, J. E., Zhang, M., Bolan, N., Mohan, D., . . Ok, Y. S. (2014). Biochar as a sorbent for contaminant management in soil and water: A review. Chemosphere, 99, 19-33.

Anderson, C. R., Condron, L. M., Clough, T. J., Fiers, M., Stewart, A., Hill, R. A., \& Sherlock, R. R. (2011). Biochar induced soil microbial community change: Implications for biogeochemical cycling of carbon, nitrogen and phosphorus. Pedobiologia, 54(5/6), 309320.

Angin, D. (2013). Effect of pyrolysis temperature and heating rate on biochar obtained from pyrolysis of safflower seed press cake. Bioresource Technology, 128(C), 593-597.

Armynah, B., Atika, Djafar, Z., Piarah, W. H., \& Tahir, D. (2018). Analysis of chemical and physical properties of biochar from rice husk biomass. The 2nd International Conference on Science, 979(1), Article 012038. doi:10.1088/1742-6596/979/1/012038

Chowdhury, Z. Z., Karim, M. Z., Ashraf, M. A., \& Khalid, K. (2016). Influence of carbonization temperature on physicochemical properties of biochar derived from slow pyrolysis of durian wood (Durio zibethinus) sawdust. Bioresource, 11(2), 3356-3372.

Chun, Y., Sheng, G. Y., Chiou, C. T., \& Xing, B. S. (2004). Compositions and sorptive properties of crop residue-derived chars. Environmental Science and Technology, 38(17), 4649-4655.

Claoston, N., Samsuri, A. W., Husni, M. H. A., \& Amran, M. M. S. (2014). Effects of pyrolysis temperature on the physicochemical properties of empty fruit bunch and rice husk biochars. Waste Management \& Research, 32(4), 331-339a.

Clemente, J. S., Beauchemin, S., Thibault, Y., MacKinnon, T., \& Smith, D. (2018). Differentiating inorganics in biochars produced at commercial scale using principal component analysis. ACS Omega, 3(6), 6931-6944.

Dang, V. M., Joseph, S., Van, H. T., Mai, T. L. A., Duong, T. M. H., Weldon, S., . . . Taherymoosavi, S. (2017). Immobilization of heavy metals in contaminated soil after mining activity by using biochar and other industrial by-products: The significant role of minerals on the biochar surfaces. Environmental Technology, 40(24), 3200-3215.

Demirbas, A., \& Arin, G. (2002). An overview of biomass pyrolysis. Energy Sources, 24(5), 471482.

Duong, V. T., Khanh, N. M., Nguyen, N. T. H., Phi, N. N., Duc, N. T., \& Xo, D. D. (2017). Impact of biochar on the water holding capacity and moisture of basalt and grey soil. Journal of Science Ho Chi Minh City Open University, 7(2), 36-43.

Fidel, R. B., Laird, D. A., \& Spokas, K. A. (2018). Sorption of ammonium and nitrate to biochars is electrostatic and pH-dependent. Scientific Reports, 8(1), Article 17627. 
Gaskin, J. W., Steiner, C., Harris, K., Da, K. C., \& Bibens, B. (2008). Effect of low-temperature pyrolysis conditions on biochar for agricultural use. Transactions of the ASABE, 51(6), 20612069.

Hassan, M., Liu,Y., Naidu, R., Parikh, S. J., Du, J., Qi, F., \& Willett, I. R. (2020). Influences of feedstock sources and pyrolysis temperature on the properties of biochar and functionality as adsorbent: A meta analysis. Journal Pre-proof, 744(20), Article 140714.

Huang, M.-L., Yucheng, Y., \& Wu, R. P. (2010). Researches on the treatment of phosphorous wastewater with oyster shells. Chinese Journal of Structural Chemistry, 29(12), 1886-1892.

Inyang, M., Gao, B., Yao, Y., Xue, Y., Zimmerman, A. R., Pullammanappallil, P., \& Cao, X. (2012). Removal of heavy metals from aqueous solution by biochars derived from anaerobically digested biomass. Bioresource Technology, 110, 50-56.

Khanmohammadi, Z., Afyuni, M., \& Mosaddeghi, M. R. (2015). Effect of pyrolysis temperature on chemical and physical properties of sewage sludge biochar. Waste Manage and Research, 33(3), 275-283.

Kragović, M., Stojmenović, M., Petrović, J., Loredo, J., Pasalić, A., Nedeljković, A., \& Ristović, I. (2019). Influence of alginate encapsulation on point of zero charge (phpzc) and thermodynamic properties of the natural and fe(iii) - modified zeolite. Elsevier, 32, 286-293.

Lehman, J., \& Joseph, S. (2015). Biochar for environmental management: Science, technology and implemention. New York, NY: Routledge.

Lehmann, J. (2007). A handful of carbon. Nature, 447(7174), 143-144.

Lehmann, J., \& Joseph, S. (2009). Biochar for environmental management: Science and technology (1st ed.). Gateshead, UK: Earthscan.

Lehmann, J., Rillig, M. C., Thies, J., Masiello, C. A., Hockaday, W. C., \& Crowley, D. (2011). Biochar effects on soil biota - A review. Soil Biology and Biochemistry, 43(9), 1812-1836.

Lima, I. M., Boateng, A. A., \& Klasson, K. T. (2010). Physicochemical and adsorptive properties of fast-pyrolysis biochars and their steam activated counterparts. Journal of Chemical Technology \& Biotechnology, 85(11), 1515-1521.

Mohan, D., Pittman, C. U. J., \& Steele, P. H. (2006). Pyrolysis of wood/biomass for bio-oil: A critical review. Energy \& Fuels, 20(3), 848-889.

Mohanty, S. K., Valenca, R., Berger, A. W., Yu, I. K. M., Xiong, X., Saunders, T. M., \& Tsang, D. C. W. (2018). Plenty of room for carbon on the ground: Potential applications of biochar for stormwater treatment. Science of The Total Environment, 625, 1644-1658.

Mukome, F. N., Zhang, X., Silva, L. C., \& Six, J. (2013). Use of chemical and physical characteristics to investigate trends in biochar feedstocks. Journal of Agricultural and Food Chemistry, 61(9), 2196-2204.

Novak, J. M., Busscher, W. J., Laird, D. L., Ahmedna, M., Watts, D. W., \& Niandou, M. A. S. (2009). Impact of biochar amendment on fertility of a Southeastern Coastal plain soil. Soil Science, 174(2), 105-112.

Ok, Y. S. (2014). Biochar as a sorbent for contaminant management in soil and water: A review. Chemosphere, 99, 19-33.

Prakongkep, N., Gilkes, R. J., Wiriyakitnateekul, W., Duangchan, A., \& Darunsontaya, T. (2013). 
The effects of pyrolysis conditions on the chemical and physical properties of rice husk biochar. International Journal of Material Science, 3(3), 97-103.

Railsback, L. B. (2006). Some fundamentals of mineralogy and geochemistry. Retrieved June 18, 2020, from http://railsback.org/FundamentalsIndex.html

Regnier, P., Lasaga, A. C., Berner, R. A., Han, O. H., \& Zilm, K. W. (1994). Mechanism of $\mathrm{CO}_{3}{ }^{2-}$ substitution in carbonate-fluorapatite: Evidence from FTIR spectroscopy, ${ }^{13} \mathrm{C}$ NMR, and quantum mechanical calculations. Amerrican Mineralogist, 79(9/10), 809-818.

Suryaningsih, S., Nurhilal, O., Yuliah, Y., \& Salsabila, E. (2017). Fabrication and characterization of rice husk charcoal bio briquettes. The 1st International Conference and Exhibition on Powder Technology Indonesia, 1927(030044), 1-6. doi:10.1063/1.5021237

Tran, T. T. (2016). Đặc điểm hoá lý của than sinh học điều chế từ vỏ trấu [Chemical and physical characteristics of biochar prepared from rice husks]. Tạp chi Khoa hoc - Đại học Huế, 120(6), 233-247.

Vinh, N. C., Nguyen, H. V., Mai, A. T. L., Lehmann, J., \& Joseph, S. (2014). Biochar treatment and its effects on rice and vegetable yields on mountainous areas of northern Vietnam. International Journal of Agricultural and Soil Science, 2(1), 5-13.

Wang, Z., Zheng, H., Luo, Y., Deng, X., Herbert, S., \& Xing, B. (2013). Characterization and influence of biochars on nitrous oxide emission from agricultural soil. Environmental Pollution, 174(C), 289-296.

Xiao, X., Chen, B., Zhu, L., \& Schnoor, J. L. (2018). Insight into multiple and multilevel structures of biochars and their potential environmental applications: A critical review. Environmental Science and Technology, 52(9), 5027-5047.

Yuan, J. H., Xu, R. K., \& Zhang, H. (2011). The forms of alkalis in the biochar produced from crop residues at different temperatures. Bioresource Technology, 102(3), 3488-3497. 